\title{
RENEWABLE ENERGY PRODUCTION PLANNING IN THE NORTH-EAST OF ITALY BY MEANS OF MULTI-CRITERIA ANALYSIS
}

\author{
Patrizia Simeoni*, Mattiussi Alessandro \\ Department of Energy Technologies \\ University of Udine, Italy \\ E-mail: patrizia.simeoni@uniud.it
}

\begin{abstract}
The excessive energy reliance on fossil fuels, together with the need to assure energy supplies and the will of reducing environmental emissions in order to comply with Kyoto's objectives, has fostered the interest towards energy savings and renewable energy. In Italy, many initiatives have been proposed regarding renewable fuels. These projects range from heat production fed by ligneous-cellulosic and undergrowth residues, to power plants coupled to anaerobic digesters fuelled by animal dejections, Combined Heating-Power (CHP) plants fed by vegetal oil together with district heating (DH), and Combined Cooling-Heating and Power (CCHP), all these projects being focused on energy saving. Such initiatives, in limited territorial contexts (Regions, Districts and Municipalities) are often in competition with each other, both for the economic incentives and the availability of energy sources. Public bodies' decisions on which plant has to be firstly financed, because of its major benefits in terms of both energy supply and inhabitants' wellbeing, have thus achieved major importance. Multicriteria analysis therefore appears as a natural tool in order to support such decisional process. This memoir shows a real case study in which the Analytic Hierarchy Process (AHP) has been applied to choose the priority of financing different energy plants, in order to reduce the dependency from fossil fuels and improve the overall efficiency of an area in the North-East of Italy. A survey on 16 municipalities in the district of Udine (Italy) is presented. Various feasible plants have been evaluated by means of the AHP regarding technical, economic, environmental and social issues. Technical, economic and environmental criteria were furthermore disaggregated into more detailed sub-criteria. A pairwise comparison between different options was then conducted - where feasible - through real design data, while a panel of experts evaluated the non-quantifiable criteria. However, having been the will of the public administration to finance projects which better complained with the Kyoto's objectives, the environmental aspect always resulted as the main criterion. As a consequence of this analysis, the best alternative has been identified in a CCHP plant serving the 'Ham District" in San Daniele, well-known on international level. The AHP has been confirmed as an efficient tool to promote communication and participation of all the actors who take part in the decisional process.
\end{abstract}

Keywords: AHP, Local Energy Planning, Prioritization, Rationalization, Renewable Energy, 


\section{Introduction}

Italian energy context, as well as other European and International countries, is characterized by an almost exclusive reliance on foreign supplies of fossil fuel. Such dependence, during the peak-oil periods of 1973 and especially during the recent 2008 outburst, highlighted the need to reduce this gap, investing in diversified strategies and alternative energy sources. Beside these mostly economic/political issues, the influence of the anthropic activities on the earth ecosystem's modifications is by now verified, therefore many International agreement (e.g. Kyoto) have been taken in order to reduce Greenhouse Gases emissions. Such factors, together with an increased political will, have led to the actual boom of the so-called 'green business', encompassing all those techs, processes and decision support systems aimed towards sustainable development of human activities.

\subsection{Energy Planning in Italy}

Energy Planning (EP) in Italy pertains the central Government's policy. Periodically, central government releases the so-called National Energy Plan (PEN), which is then transferred to regional and provincial authorities. The latter, following the common guidelines, develop their own Regional Energy Plan (PEN) and Provincial Energy Plan (PEP). Eventually, some municipalities -the one with more then 40.000 inhabitants - develop their own Municipal Energy Plan (PEC). Beside these traditional institutional divisions, aggregations of smaller municipalities have been present in order to promote areas with homogenous economic, industrial and social backgrounds, in addition to geographical closeness. Such aggregations have been recently (2006) denominated 'ASTER' (literally translated in 'Areas towards territorial development') and their activities focus on economic development, local promotion and management and preservation of local environment and landscape. Issues regarding energy and infrastructure, therefore, fall on their competences. In this sector, however, decisional process is complicated by the limited territorial context, affecting three major problems:

1. Budget allocated to energy and environmental projects is limited;

2. Suggested projects are often inhomogeneous, with technical, economic, and environmental features extremely variable;

3. Actors involved in the decisional process are many, and they present different cultural backgrounds, responding therefore differently to similar stimuli;

The first issue lead to the need of prioritizing different alternatives and, given the two other above issues, these latter need to be evaluated in a multi-criteria process. The Analytic Hierarchy Process (AHP), proposed by Saaty (1980) is one of the commonly-used method to evaluate different options in a multi-criteria way.

Literature analysis on the AHP's application in the energy/environmental industry shows that many authors focus on specific aspects such as risk management (Cahyani, 2003), different tools and incentives to promote energy savings measures (Kablan, 2004), indexes to estimate sustainable development (Xiaohua e Zhenmin 2002), and medium/long term research strategies in the energy sector (Kagazyo, 1993). Particular interest is given to the multi-criteria evaluation of the barriers towards energy efficiency improvements on small-scale companies (Nagesha e Balachandra, 1996), towards application of cleaner technologies in developing countries (Wijayatunga et al, 1996), or towards the spreading of high-efficiency cooking stoves and small-scale anaerobic digesters (Limmeechokchai e Chawana, 1997). Among the more general studies, Kabir e Shihan (2003) applied the AHP to evaluate various renewable plants in Bangladesh, while Jaber et al (2008) analyzed traditional and renewable alternatives for household space heating. Lee et al. (1996) studied the optimal choice and location of wind farms by means of the AHP.

\section{The 'Comunità Collinare del Friuli Venezia Giulia'}

In the Italian region of Friuli Venezia Giulia (FVG), located in the North-East of the country, an ASTER have been instituted among 16 municipalities located in the pre-alpine part of the region. The 
ASTER is called "Comunità Collianare del Friuli Venezia Giulia" (CCFVG) and its location is shown in Figure 1.

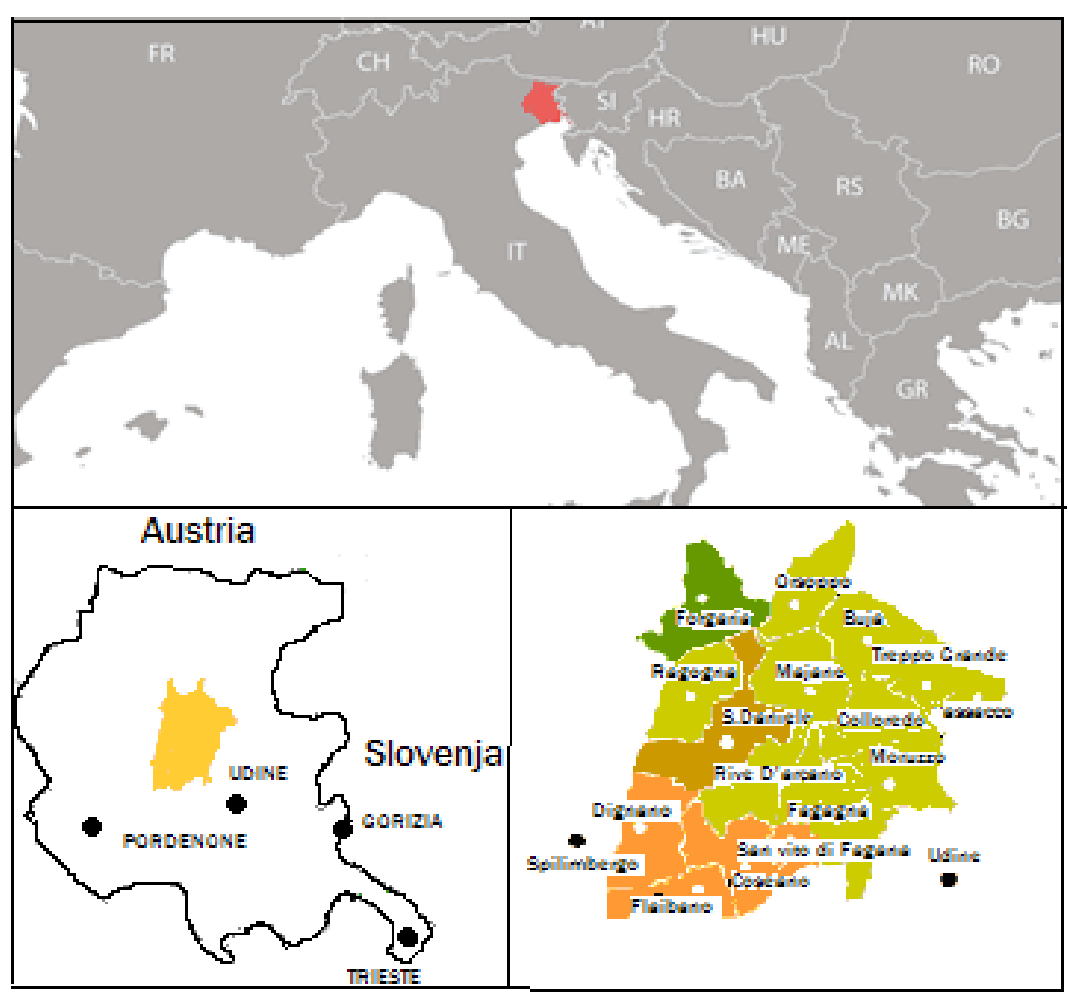

Figure 1: Location of the 'Comunità Collinare del Friuli Venezia Giulia'

The CCFVG encompasses almost 53.000 inhabitants (FVG: 1.250 .000 ) and it extends over $360 \mathrm{~km}^{2}$ (FVG: $7.850 \mathrm{~km}^{2}$ ). The ASTER is characterized by an economic structure mainly agrarian, even though industrial companies with National and International relevance are present in this area. In Table 1 some peculiar characteristics of the single municipalities in the CCFVG are shown.

Table 1: Main features of the CCFVG municipalities

\begin{tabular}{|l|l|l|l|l|}
\hline \multicolumn{1}{|c|}{ Municipality } & Inhabitants & $\begin{array}{c}\text { Area } \\
{\left[\mathbf{k m}^{2}\right]}\end{array}$ & $\begin{array}{c}\text { Altitude [m } \\
\text { AMSL] }\end{array}$ & \multicolumn{1}{|c|}{ Economy based upon } \\
\hline Buia & 6,674 & 27.88 & 213 & Agricolture, Industry \\
\hline Cassacco & 2,849 & 11.63 & 179 & Agricolture. \\
\hline Colloredo di Monte Albano & 2,154 & 21.58 & 218 & Agricolture. \\
\hline Coseano & 2,214 & 23.86 & 121 & Agricoltura; Dairy. \\
\hline Dignano & 2,326 & 27.17 & 112 & Agricolture, Small industry \\
\hline Fagagna & 6,035 & 37.02 & 177 & Confectionery industry \\
\hline Flaibano & 1,183 & 17.24 & 104 & Agricolture. \\
\hline Forgaria nel Friuli & 1,907 & 29.18 & 270 & Tertiary, Construction Agricolture. \\
\hline Majano & 5,877 & 28.1 & 170 & Agricolture, Industry \\
\hline Moruzzo & 2,170 & 17.88 & 264 & Agricolture. \\
\hline Osoppo & 2,889 & 22.16 & 184 & Steel Industry, Agricolture. \\
\hline Ragogna & 3,006 & 22.42 & 235 & $\begin{array}{l}\text { Agricolture, small craftmade and } \\
\text { building companies. }\end{array}$ \\
\hline Rive d'Arcano & 2,284 & 22.48 & 175 & $\begin{array}{l}\text { Agricolture, small craftmade } \\
\text { companies }\end{array}$ \\
\hline San Daniele del Friuli & 7,893 & 34.68 & 252 & $\begin{array}{l}\text { Food industry (ham); small } \\
\text { craftmade companies; Tertiary; }\end{array}$ \\
\hline San Vito di Fagagna & 1,617 & 8.54 & 135 & Agricolture. \\
\hline Treppo Grande & 1,754 & 11.31 & 231 & Agricolture; Costruction industry \\
\hline \multicolumn{1}{|c|}{ CC FVG } & $\mathbf{5 2 , 8 3 2}$ & $\mathbf{3 6 3 . 1 3}$ & & - \\
\hline
\end{tabular}

\footnotetext{
${ }^{1}$ Literally translated in 'Hilly Community of Friuli Venezia Giulia”
} 


\subsection{The energy optimization project}

In 2008 the CCFCG commissioned the University of Udine, located near the ASTER, to implement a feasibility study on the subject "Identification of the potential energy recovery from agro-industrial residues and the utilization of renewable sources inside the Comunità Collianare of Friuli Venezia Giulia”. This study quantified and localized residues from agriculture production (mainly maize) and from the zootechnical breeding and slaughterhouses. Moreover, in situ inspection allowed to study the potential savings achievable through hydro-energy exploitation of rivers and creeks, while a preliminary audit was conducted in some of the firms of the CCFVG to identify potential 'energy fields' - which are areas characterized by complementary energy demands - in order to exploit the centralized production of a combined heating, cooling and power plant.

This study identified 5 major projects, that is:

1. Small-scale hydropower plants located in four local creeks;

2. Solar power plants partially integrated to local buildings;

3. Organic residues' recovery and anaerobic digestion in order to produce biogas, subsequently feeding a power plant located in barycentric position with respect to residues' availability;

4. Combined Cooling and Heating Plant (CCHP) fuelled by rapeseed oil growth close to the plant in the industrial area in the municipality of Fagagna;

5. Combined Cooling and Heating Plant (CCHP) fuelled by natural gas serving the food district located in the municipality of San Daniele and its local hospital.

A brief description of these alternatives is presented in the next paragraphs, together with the relative codes which will be used later on in the paper.

Alternative 1: Small-scale hydropower plant (code A1)

The opportunity of realizing small hydro-power plants has been studied, in order to exploit the limited hydraulic jump of the CCFVG. However, the optimal sizing of these plants has to be subordinated to a more detailed study on the water flows during the year and on the possible issues which can compromise the plant's construction (e.g. marine fauna's damaging). The potentiality of the identified plants, together with the relative municipality, are shown in Table 2.

Table 2: Hydro-power plants identified and relative potentiality

\begin{tabular}{|c|c|}
\hline Comune & Potenza \\
\hline Osoppo & $65 \mathrm{~kW}$ \\
\hline Buja & $45 \mathrm{~kW}$ \\
\hline Dignano & $45 \mathrm{~kW}$ \\
\hline S. Daniele & $170 \mathrm{~kW}$ \\
\hline
\end{tabular}

Alternative 2: Solar Power Plants (A2)

Power production from photovoltaic plants is an alternative applicable to all municipalities in the CCFVG, therefore it was not considered appropriate to evaluate this alternative in any single specific municipality. If anything, the potential power producible was estimated by using the region-specific average solar radiations, through the EU portal www.pvgis.com. The base-plant proposed to every municipality is partially integrated to the actual building structure and it does not present any tracking system. The orientation is 'South' and the angle with respect to the horizon is $35^{\circ}$, in order to optimize solar radiation's capture. The value chosen for the plant size was limited to 200 peak kilowatts, given the uncertainties regarding costs and performances of this plant type.

Alternative 3: Anaerobic Digester and Biogas Power Plant (A3)

Fermentative processes take place in environment deprived of oxygen and are favoured by the insertion of particular bacteria, which catalyze the reaction. The output of this process is a mixture of gas mainly consisting of Methane and Carbon Dioxide. The former - accounting more than the $50 \%$ of the biogas - can be used to produce power or heat. The identified solution in the study is an anaerobic 
digester fed by almost 1000 tonnes/year of food residues and maize scrap, associated with a $500 \mathrm{~kW}_{\mathrm{e}}$ power plant. This solution promotes recovery of the agricultural, zootechnical and food-processing residues, while the plant would be located in the municipality of Rive D'Arcano, situated in a barycentric position with respect to the feeding material's availabilities.

\section{Alternative 4: Rapeseed oil plant (A4)}

In the municipality of Fagagna, given the various energy requests in the industrial area of the commune and the agricultural vocation of the CCFVG, the possibility of installing a power plant fed by rapeseed oil has been studied. The project, which has already been given the approval by local authorities, is made up of three stages:

a) Construction of a combined heat-power plant of $4 \mathrm{MW}_{\mathrm{e}}$ and external supply of bio-fuel;

b) Construction of a district heating network (estimated length: 2,5km) in order to feed the near industrial area, together with the eventual construction of absorption chilling groups, particularly needed by a company in that area;

c) Agreement with the local farmers in order to produce in the CCFVG agricultural areas the rapeseed oil needed by the plant.

\section{Alternative 5: CCHP gas plant in San Daniele (A5)}

The municipality of San Daniele is well-known on International scale for the production of its typical cured ham. The opportunity of building a centralized combined cooling and heating plant has been investigated, in order to diminish the energy costs of the 26 companies of the sector located in this area. The companies and the plant (estimated potentiality about $7 \mathrm{MW}_{\mathrm{e}}$ ) would be linked by a district heating network (estimated length: $4 \mathrm{~km}$ ) which would feed also the local Civil Hospital. The plant would be fuelled by a non-renewable source (natural gas), but it could represent a major opportunity for energy savings through the centralization of the energy production processes.

\section{Hierarchy Analysis}

It can be noted from the previous paragraphs that the alternatives proposed in the study, all of them being feasible from a technical and economic viewpoint, are extremely inhomogeneous and impact in different ways over the limited territorial context of CCFVG. The latter, as it has been discussed before, has often limited budget and therefore it has to direct its choice toward the alternative which represents the optimal trade-off among the various evaluation criteria. The Analytic Hierarchy Process, proposed by Saaty (1980), allows to break down the issues related to the decisional process and, after the pairwise comparison among the alternatives, it leads to the reconstruction of the model and the identification of the trade-off solution. Generally speaking, the criteria to evaluate a project in the energy and environmental field are four, that is:

1) Technical criteria: plant efficiency, productivity, useful life, etc.;

2) Economic criteria: investment cost, operative costs and revenues, payback, etc.;

3) Environmental criteria: Greenhouse effect, renewable energy, visual impact, etc;

4) Social criteria: public acceptance, side-effects on the environment, etc.

Traditional approach towards AHP is made up of mainly three stages: modelling, pairwise comparison and synthesis, which will be analyzed in the next paragraphs.

\subsection{Modelling}

The main goal chosen for this analysis is the "choice of the best solution among the ones identified for the CCFVG". The criteria - and their relative codification - utilized for the alternatives' evaluation are:

- C1. Energy Covering, broken up into two sub-criteria "Electrical Energy Covering” (C1a) and "Thermal Energy Covering" (C1b) which represents the ratio between the electricity (or thermal energy) produced by the alternative and the total (heat or power) requirement of the CCFVG.

- C2. Energy Conversion Efficiency. First Law's Efficiency, taking into account both the power and, in case, the thermal efficiency. 
- C3. Technological Reliability, in terms of industrial development of plant technology and suppliers' and machines' availability;

- C4. Useful Life of the Plant, before it has to be dismantled or subjected to a major maintenance program;

- C5. Environmental impact, divided into two sub-criteria of 'avoided green house effect' (C5a) in terms of equivalent tonnes of $\mathrm{CO}_{2}$ and 'visual impact' on the landscape (C5b);

- C6. Social acceptance of the plant, in terms of plant impact over the local community due to, for example, opinion or bias rooted in the common thinking;

- C7. Total costs of the plant, in terms of initial investment costs (C7a) and the costs and/or revenues during its operation, which are taken into account in the value of the payback (C7b);

- $\quad$ C8. The easiness for plant building, through the construction time value ;

The alternatives were analyzed in §2.1. The whole model used for the AHP is represented in Figure 2.

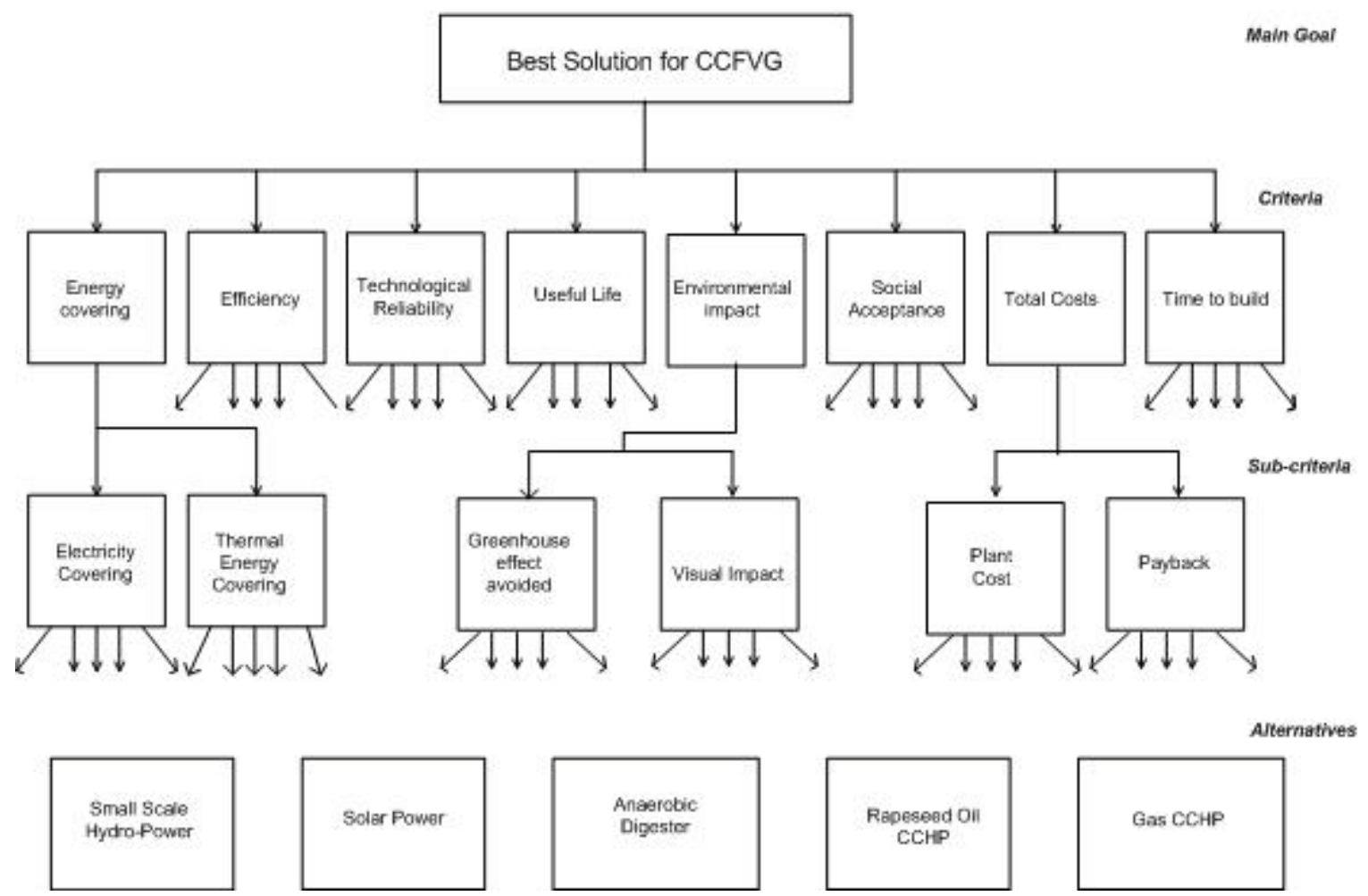

Figure 2: Reference system model used for the AHP

\subsection{Pairwise Comparison}

Evaluation of the alternatives with respect to criteria and sub-criteria

The analysis of criteria and sub-criteria highlights that, while some of them are directly or indirectly quantifiable, others, like the visual impact or the social acceptance, are not directly assessable. Anyway, the method chosen to compare the alternatives is similar, and it encompasses three stages, that is:

1. A number of $i$ alternatives $\left(A_{1}, A_{2}, \ldots, A_{i}\right)$ has to be compared with respect to a common criteria $C_{j}$, being known, for each alternative $i$, the value $v_{i}$, that is a numerical value representing the performance of the alternative A with respect to the criterion $C_{j}$. For the case of quantifiable criteria, design data are utilized, while qualitative criteria has been evaluated on a 1-to-10 scale by a panel of experts. The value $v_{\max }$ is then calculated, that is the maximum $v_{i}$ among the alternatives. Each $v_{i}$ is divided by $v_{\max }$, obtaining a value $\mathrm{V}_{\mathrm{i}}$ for each $i$ alternative, logically included from 0 to 1 (eq.1).

$$
\mathrm{V}_{\mathrm{i}}=\mathrm{v}_{\mathrm{i}} / \mathrm{v}_{\max }, \text { con } 0 \leq \mathrm{V}_{\mathrm{i}} \leq 1
$$


2. Pairwise comparison among alternatives, done by subtracting the values calculated in the previous stage. For example, the comparison between two alternatives $A_{1}$ e $A_{2}$ is done by calculating the difference between $\mathrm{V}_{1}$ and $\mathrm{V}_{2}$ and considering its absolute value (eq. 2):

$$
\mathrm{X}_{12}=\mathrm{X}_{21}=\left|\mathrm{V}_{1}-\mathrm{V}_{2}\right|
$$

3. Relate the values obtained in the previous stage - through proportion and considering eventual approximation by excess or defect - to the 1 to 9 scale, as traditionally used in the AHP model for pairwise comparison

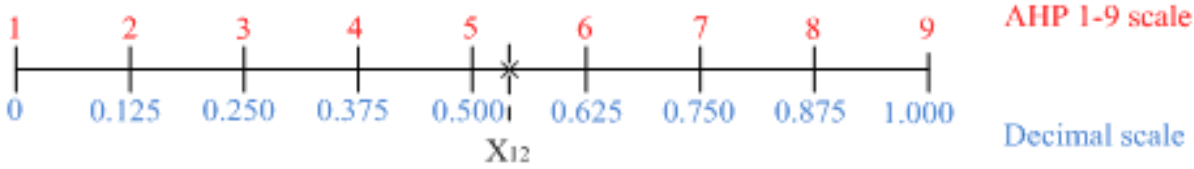

Figure 3: Nomogram used to refer the decimal values to the 1-9 scale

Qualitative and quantitative ${ }^{2}$ data used for the pairwise comparison are shown in Table 3.

Table 3: Synthesis of the quantitative and qualitative features of the identified alternatives

\begin{tabular}{|c|c|c|c|c|c|c|}
\hline & & \multicolumn{5}{|c|}{ Alternatives } \\
\hline & U.M & A1 & A2 & A3 & A4 & A5 \\
\hline \multicolumn{7}{|l|}{ Quantitative Criteria } \\
\hline Nominal Power & $\mathrm{kW}_{\mathrm{e}}$ & 325 & 200 & 500 & 4,000 & 7,000 \\
\hline Efficiency & $\%$ & 73.00 & 10.00 & 39,00 & 80.95 & 86.00 \\
\hline Electricity Output & $\mathrm{kWh} / \mathrm{y}$ & $1,440,000$ & 200,500 & $3,504,000$ & $32,000,000$ & $49,056,000$ \\
\hline Thermal Output & $\mathrm{kWh} / \mathrm{y}$ & 0 & 0 & 0 & $23,048,000$ & $35,810,880$ \\
\hline Time to Build & months & 12 & 3.5 & 20 & 30 & 18 \\
\hline Greenhouse effect avoided & $\mathrm{kg} \mathrm{CO} 2_{\mathrm{eq}}$ & 110,275 & 792,000 & $1,927,200$ & $15,270,744$ & $23,507,145$ \\
\hline Plant Cost & $\$$ & $1,316,250$ & 952,500 & $4,007,438$ & $3,903,750$ & $10,125,000$ \\
\hline Payback & years & 8.7 & 45.4 & 10.9 & 6.1 & 10.5 \\
\hline Useful Plant Life & years & 30 & 20 & 10 & 20 & 15 \\
\hline \multicolumn{7}{|l|}{ Qualitative Criteria } \\
\hline Technological Reliability & - & 5 & 6 & 3 & 10 & 8 \\
\hline Social Acceptance & - & 8 & 10 & 6 & 5 & 5 \\
\hline Visual Impact & - & 6 & 3 & 1 & 9 & 10 \\
\hline
\end{tabular}

As an example, the comparison among the alternatives with respect to the sub-criterion 'Plant Cost' (code: C7a) is considered. Design values, as shown in Table 4, are normalized dividing them by the maximum value of $13.5 \mathrm{M} €$, the investment costs of $A 5$, and the $V_{i}$ values (§3.2.1) are obtained.

Table 4: Example referred to plant costs and normalized ratio of the alternatives

\begin{tabular}{|c|c|c|}
\hline & \multicolumn{2}{|c|}{ C7a } \\
\hline & $\mathbf{v i}$ & $\mathbf{v}_{\mathbf{i}}=\mathbf{v i} / \mathbf{v}_{\max }$ \\
\hline A1 & $1,316,250$ & 0.13 \\
\hline A2 & 952,500 & 0.09 \\
\hline A3 & $4,007,438$ & 0.40 \\
\hline A4 & $3,903,750$ & 0.39 \\
\hline A5 & $10,125,000$ & 1.00 \\
\hline
\end{tabular}

\footnotetext{
${ }^{2}$ Economic calculations were made considering the average Italian costs of electricity, equal to $0.14 € / \mathrm{kWh}$, and that of Natural Gas, the common source used for heating, equal to $0.35 € / \mathrm{Nm}^{3}$, fixing the exchange rate at 0.75 $€ / \$$. No incentives were considered. Technical data were taken from the above-cited feasibility study.
} 
After having found these values, each pair of alternatives are compared by subtraction, as it is done in Table 5. The alternatives are firstly ranked (from the maximum value of $\mathrm{V}_{\mathrm{i}}$, necessarily equal to 1 , to the minimum value reported) to better suit the following comparison, which led to the values $\mathrm{X}$ (§3.2.2).

Table 5: Example of pairwise comparison among alternatives using decimal values

\begin{tabular}{|l|l|l|l|l|l|}
\hline & \multicolumn{1}{|c|}{ A5 } & \multicolumn{1}{c|}{ A3 } & \multicolumn{1}{c|}{ A4 } & \multicolumn{1}{c|}{ A1 } & A2 \\
\hline A5 & 1 & \multicolumn{1}{c|}{} & & \\
\hline A3 & $1-0.4=0.6$ & 1 & & & \\
\hline A4 & $1-0.039=0.61$ & $0.4-0.39=0.01$ & 1 & & \\
\hline A1 & $1-0.13=0.87$ & $0.4-0.13=0.27$ & $0.39-0.13=0.26$ & 1 & \\
\hline A2 & $1-0.09=0.91$ & $0.4-0.09=0.31$ & $0.39-0.09=0.3$ & $0.13-0.09=0.04$ & 1 \\
\hline
\end{tabular}

Eventually, values inside Table 5 are referred to the traditional 1 to 9 scale of the AHP. In this example, the comparison between the combined cooling heating and power plant (A5) and rapeseed oil plant (A4) lead to a value of .61, which is 'translated' in a factor 6 in the AHP scale (Figure 4). With regards to the total investment costs, therefore, the A4 is 'strongly to very strongly' more important than A5, which was predictable because of the more than halved investment needed for A4. The confrontation between the various alternatives leads to the matrix represented in Table 6 .

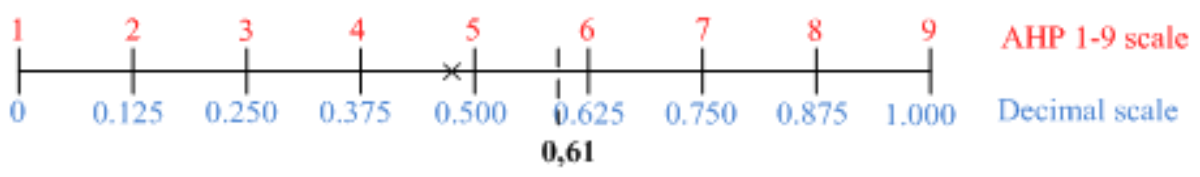

Figure 4: Example of referring the decimal distance among alternatives to the 1-9 scale

Table 6: Example of matrix for alternatives' comparison with respect to the sub-criteria 'Plant Cost'

\begin{tabular}{|r|r|r|r|r|r|}
\hline C7a & A1 & A2 & A3 & A4 & A5 \\
\hline A1 & 1 & 1 & 3 & 3 & 8 \\
\hline A2 & & 1 & 3 & 3 & 8 \\
\hline A3 & & & 1 & 1 & 6 \\
\hline A4 & & & & 1 & 6 \\
\hline A5 & & & & & 1 \\
\hline
\end{tabular}

All the pairwise comparisons among alternatives are transcribed in Table 7, together with the consistency ratio (C.R.) which always resulted less then 0.1 .

Table 7: Synthesis of the pairwise comparisons among the alternatives (A1-A5) with respect to the chosen

\begin{tabular}{|l|c|c|c|c|c|}
\hline C1 $a$ & A1 & A2 & A3 & A4 & A5 \\
\hline A1 & 1 & 1 & 1 & $1 / 6$ & $1 / 9$ \\
\hline A2 & & 1 & $1 / 2$ & $1 / 6$ & $1 / 9$ \\
\hline A3 & & & 1 & $1 / 6$ & $1 / 8$ \\
\hline A4 & & & & 1 & $1 / 4$ \\
\hline A5 & & & & & 1 \\
\hline
\end{tabular}

C.R. 0.0406

\begin{tabular}{|l|c|c|c|c|c|}
\hline C3 & A1 & A2 & A3 & A4 & A5 \\
\hline A1 & 1 & $1 / 2$ & 3 & $1 / 5$ & $1 / 3$ \\
\hline A2 & & 1 & 3 & $1 / 4$ & $1 / 3$ \\
\hline A3 & & & 1 & $1 / 7$ & $1 / 5$ \\
\hline
\end{tabular}

criteria and sub-criteria

\begin{tabular}{|l|c|c|c|c|c|}
\hline C1b & A1 & A2 & A3 & A4 & A5 \\
\hline A1 & 1 & 1 & 1 & $1 / 6$ & $1 / 9$ \\
\hline A2 & & 1 & 1 & $1 / 6$ & $1 / 9$ \\
\hline A3 & & & 1 & $1 / 6$ & $1 / 9$ \\
\hline A4 & & & & 1 & $1 / 4$ \\
\hline A5 & & & & & 1 \\
\hline
\end{tabular}

C.R. 0.0266

\begin{tabular}{|l|c|c|c|c|c|}
\hline C4 & A1 & A2 & A3 & A4 & A5 \\
\hline A1 & 1 & 4 & 6 & 4 & 5 \\
\hline A2 & & 1 & 4 & 1 & 2 \\
\hline A3 & & & 1 & $1 / 4$ & $1 / 2$ \\
\hline
\end{tabular}

\begin{tabular}{|l|c|c|c|c|c|}
\hline C2 & A1 & A2 & A3 & A4 & A5 \\
\hline A1 & 1 & 7 & 4 & $1 / 2$ & $1 / 2$ \\
\hline A2 & & 1 & $1 / 4$ & $1 / 8$ & $1 / 8$ \\
\hline A3 & & & 1 & $1 / 5$ & $1 / 5$ \\
\hline A4 & & & & 1 & 1 \\
\hline A5 & & & & & 1 \\
\hline
\end{tabular}

C.R. 0.0313

\begin{tabular}{|l|c|c|c|c|c|}
\hline C5a & A1 & A2 & A3 & A4 & A5 \\
\hline A1 & 1 & 1 & 1 & $1 / 6$ & $1 / 9$ \\
\hline A2 & & 1 & $1 / 2$ & $1 / 6$ & $1 / 9$ \\
\hline A3 & & & 1 & $1 / 5$ & $1 / 8$ \\
\hline
\end{tabular}




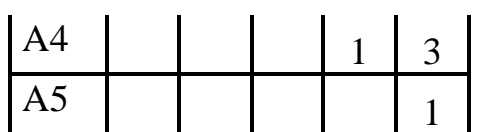

C.R. 0.0392

\begin{tabular}{|l|c|c|c|c|c|}
\hline$C 5 b$ & A1 & A2 & A3 & A4 & A5 \\
\hline A1 & 1 & 3 & 5 & $1 / 3$ & $1 / 4$ \\
\hline A2 & & 1 & 3 & $1 / 6$ & $1 / 7$ \\
\hline A3 & & & 1 & $1 / 7$ & $1 / 8$ \\
\hline A4 & & & & 1 & $1 / 2$ \\
\hline A5 & & & & & 1 \\
\hline
\end{tabular}

C.R. 0.0457

\begin{tabular}{|l|c|c|c|c|c|}
\hline C7b & A1 & A2 & A3 & A4 & A5 \\
\hline A1 & 1 & 7 & 1 & 1 & 1 \\
\hline A2 & & 1 & $1 / 7$ & $1 / 7$ & $1 / 7$ \\
\hline A3 & & & 1 & $1 / 2$ & 1 \\
\hline A4 & & & & 1 & 2 \\
\hline A5 & & & & & 1 \\
\hline
\end{tabular}

C.R. 0.0173

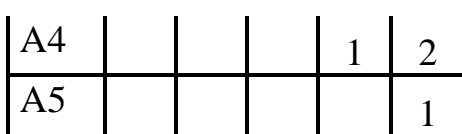

C.R. 0.0240

\begin{tabular}{|l|c|c|c|c|c|}
\hline C6 & A1 & A2 & A3 & A4 & A5 \\
\hline A1 & 1 & $1 / 3$ & 3 & 3 & 3 \\
\hline A2 & & 1 & 4 & 5 & 5 \\
\hline A3 & & & 1 & 2 & 2 \\
\hline A4 & & & & 1 & 1 \\
\hline A5 & & & & & 1 \\
\hline
\end{tabular}

C.R. 0.0250

\begin{tabular}{|c|c|c|c|c|c|}
\hline C8 & A1 & A2 & A3 & A4 & A5 \\
\hline A1 & 1 & $1 / 3$ & 3 & 6 & 3 \\
\hline A2 & & 1 & 5 & 8 & 5 \\
\hline A3 & & & 1 & 4 & $1 / 2$ \\
\hline A4 & & & & 1 & $1 / 4$ \\
\hline A5 & & & & & 1 \\
\hline
\end{tabular}

C.R. 0.0493

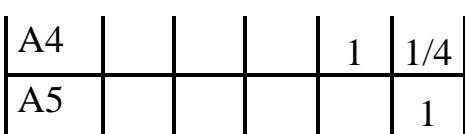

C.R. 0.0354

\begin{tabular}{|l|l|l|l|l|l|}
\hline C7a & A1 & A2 & A3 & A4 & A5 \\
\hline A1 & 1 & 1 & 3 & 3 & 8 \\
\hline A2 & & 1 & 3 & 3 & 8 \\
\hline A3 & & & 1 & 1 & 6 \\
\hline A4 & & & & 1 & 6 \\
\hline A5 & & & & & 1 \\
\hline
\end{tabular}

C.R. 0.0405

Evaluation of sub-criteria with respect to the above criterion

In order to evaluate the weight of the sub-criteria with respect to the above criterion, given the little number of judgment needed, the traditional AHP 1-9 scale has been directly utilized by the evaluation panel. Results are shown in Table 8.

Table 8: Synthesis of the pairwise comparisons among sub-criteria with respect to the above criteria

\begin{tabular}{|c|c|c|}
\hline C1 & C1a & C1b \\
\hline C1a & 1 & 3 \\
\hline C1b & & 1 \\
\hline
\end{tabular}

\begin{tabular}{|c|c|c|}
\hline $\mathbf{C 5}$ & $\mathrm{C} 5 \mathrm{a}$ & $\mathrm{C} 5 \mathrm{~b}$ \\
\hline $\mathrm{C} 5 \mathrm{a}$ & 1 & 3 \\
\hline C5b & & 1 \\
\hline
\end{tabular}

\begin{tabular}{|c|c|c|}
\hline C7 & C7b & C7b \\
\hline C7a & 1 & $1 / 3$ \\
\hline C7b & & 1 \\
\hline
\end{tabular}

Evaluation of criteria with respect to the main goal

During this last stage of the comparison, weights of the single criteria with respect the main goal have not been fixed in order to make the method more consistent to the real decisional process,. In real situations, as a matter of fact, the decision maker could present different backgrounds, and therefore a unique synthesis would have not faithfully reflected the common decisional process. Specifically, three different viewpoints have been considered:

- Technical/Engineering viewpoint, favouring solutions with higher efficiencies, yields and reliability, together with affordable expenses;

- Administrative viewpoint, which favours the alternatives more feasible from the economic perspective, together with social acceptable solutions for the community;

- Environment-friendly viewpoint, supporting solutions characterized by minimum environmental impact and generally unaware of the technical and economical features.

The weights associated to each single criterion with respect to the final goal are presented in Table 9 . 
Table 8: Judgments of criteria with respect to the main goal following a triple viewpoint

\begin{tabular}{|c|c|c|c|c|c|}
\hline \multicolumn{2}{|c|}{ Technical/Engineering } & \multicolumn{2}{|c|}{ Administrative } & \multicolumn{2}{|c|}{ Environment-friendly } \\
\hline CRITERI & Rating & CRITERI & Rating & CRITERI & Rating \\
\hline Efficiency & 10 & Total Costs & 10 & Environmental Impact & 10 \\
\hline Energy Covering & 9 & Environmental Impact & 10 & Social Acceptance & 8 \\
\hline Total Costs & 7 & Social Acceptance & 9 & Efficiency & 5 \\
\hline Technology Reliability & 7 & Time to build & 7 & Energy Covering & 5 \\
\hline Time to build & 6 & Efficiency & 5 & Useful life & 5 \\
\hline Useful life & 5 & Energy Covering & 5 & Technology Reliability & 5 \\
\hline Environmental Impact & 3 & Useful life & 4 & Time to build & 5 \\
\hline Social Acceptance & 1 & Technology Reliability & 4 & Total Costs & 3 \\
\hline
\end{tabular}

These values are used in the same fashion of the previous criteria, following the method presented in $\S 3.2 .1$ - §3.2.3, and lead to the matrixes shown in Tables 9

Table 9: Criteria's comparison with respect to the main goal: three different perspectives

\begin{tabular}{|c|c|c|c|c|c|c|c|c|}
\hline & C1 & C2 & C3 & C4 & C5 & C6 & C7 & C8 \\
\hline C1 & 1 & $1 / 2$ & 3 & 4 & 6 & 7 & 3 & 3 \\
\hline C2 & & 1 & 3 & 5 & 7 & 8 & 3 & 4 \\
\hline C3 & & & 1 & 3 & 4 & 6 & 1 & 2 \\
\hline C4 & & & & 1 & 3 & 4 & 3 & $1 / 2$ \\
\hline C5 & & & & & 1 & 3 & $1 / 4$ & $1 / 3$ \\
\hline C6 & & & & & & 1 & $1 / 6$ & $1 / 5$ \\
\hline C7 & & & & & & & 1 & 2 \\
\hline C8 & & & & & & & & 1 \\
\hline
\end{tabular}

Criteria’s Comparison by the engineering perspective

\begin{tabular}{|c|c|c|c|c|c|c|c|c|}
\hline & C1 & C2 & C3 & C4 & C5 & C6 & C7 & C8 \\
\hline C1 & 1 & 1 & 1 & 1 & $1 / 5$ & $1 / 3$ & $1 / 3$ & 1 \\
\hline C2 & & 1 & 1 & 1 & $1 / 5$ & $1 / 3$ & 3 & 1 \\
\hline C3 & & & 1 & 1 & $1 / 5$ & $1 / 2$ & 3 & 1 \\
\hline C4 & & & & 1 & $1 / 5$ & $1 / 3$ & 3 & 1 \\
\hline C5 & & & & & 1 & 3 & 7 & 5 \\
\hline C6 & & & & & & 1 & 5 & 2 \\
\hline C7 & & & & & & & 1 & $1 / 3$ \\
\hline C8 & & & & & & & & 1 \\
\hline
\end{tabular}

Criteria’s Comparison by the environmental perspective

\begin{tabular}{|c|c|c|c|c|c|c|c|c|}
\hline & C1 & C2 & C3 & C4 & C5 & C6 & C7 & C8 \\
\hline C1 & 1 & 1 & 2 & 2 & $1 / 5$ & $1 / 4$ & $1 / 5$ & $1 / 3$ \\
\hline C2 & & 1 & 2 & 2 & $1 / 5$ & $1 / 4$ & $1 / 5$ & $1 / 3$ \\
\hline C3 & & & 1 & 1 & $1 / 6$ & $1 / 5$ & $1 / 6$ & $1 / 3$ \\
\hline C4 & & & & 1 & $1 / 6$ & $1 / 5$ & $1 / 6$ & $1 / 3$ \\
\hline C5 & & & & & 1 & 2 & 1 & 3 \\
\hline C6 & & & & & & 1 & $1 / 2$ & 3 \\
\hline C7 & & & & & & & 1 & 3 \\
\hline C8 & & & & & & & & 1 \\
\hline
\end{tabular}

Criteria's Comparison by the administrative perspective

\subsection{Synthesis}

Alternatives were assessed following the criteria presented in $\S 3.1$ and the methodology discussed in $\$ 3.2 .1$ - \$3.2.3 with respect to the triple perspective, namely engineering, environmental and administrative. The AHP's results are shown in Table 9.

\begin{tabular}{|c|c|c|c|}
\hline Alternatives & Ideals & Normals & Raw \\
\hline A5 & 1 & 0.319022 & 0.134646 \\
\hline A4 & 0.839627 & 0.267860 & 0.113052 \\
\hline A1 & 0.630775 & 0.201231 & 0.084931 \\
\hline A2 & 0.438030 & 0.139742 & 0.058979 \\
\hline A3 & 0.226143 & 0.072145 & 0.030449 \\
\hline
\end{tabular}

Alternatives' ranking with respect to the engineering perspective

\begin{tabular}{|c|c|c|c|} 
Alternatives & Ideals & Normals & Raw \\
\hline A5 & 1 & 0.276915 & 0.107203 \\
\hline A4 & 0.780401 & 0.216105 & 0.083661 \\
\hline A2 & 0.728456 & 0.201720 & 0.078092 \\
\hline A1 & 0.709057 & 0.196348 & 0.076013 \\
\hline A3 & 0.393307 & 0.108912 & 0.042163 \\
\hline
\end{tabular}

Alternatives' ranking with respect to the administrative perspective 


\begin{tabular}{|c|c|c|c|}
\hline Alternatives & Ideals & Normals & Raw \\
\hline A5 & 1 & 0.332062 & 0.133237 \\
\hline A4 & 0.691112 & 0.229492 & 0.092082 \\
\hline A2 & 0.554937 & 0.184273 & 0.073938 \\
\hline A1 & 0.524428 & 0.174142 & 0.069873 \\
\hline A3 & 0.241014 & 0.080031 & 0.032112 \\
\hline
\end{tabular}

Alternatives' ranking with respect to the environmental perspective

The AHP revealed that the alternative A5 - the CCHP plant serving the food district of San Daniele appears to be the most relevant choice among the opportunities identified for the CCFVG. The three different perspectives analyzed revealed that no significant variation was reported in the relative comparison among alternatives. The only change happened in the engineering perspective, whose ranking revealed a preference of the small-scale hydropower plant (A1) respect the photovoltaic systems (A2).

\section{Conclusions}

In this paper the AHP was used to evaluate alternatives for energy reduction or renewable energy's exploitation for a group of municipalities in the North East of Italy. Decisional process in such limited contexts needs to address those alternatives which better suits the different objectives of the stakeholders. The AHP proved to be a useful tool to assess various alternatives, even if these latter were characterized by different performances with respect to the criteria utilized. Qualitative data were assessed by a panel of experts, while quantitative data - taken from the design specifications - were referred to (i.e. divided by) the actual values registered in the municipalities. This operation, even if it logically does not affect the AHP results - is useful to assess the alternatives not only in general terms, but for site-specific study, which is a precondition of every decisional process in local contexts. Among the various alternatives proposed in the study, the choice of building a CCHP plant serving the local food district and the civil hospital in the municipality San Daniele appeared to be the best choice for each of the three viewpoints considered in the analysis, namely engineering, administrative and environmental. The preference accorded to a rationalization project, rather than to other options introducing renewable sources, confirm the actual need of comprehensive multi-criteria studies of the various alternatives before undertaking projects in the energy and environmental industry.

Further investigation is currently being carried out in order to evaluate the robustness of this evaluation by means of a sensitivity analysis, while future works will require a more detailed criteria resolution to determine the most relevant factors to evaluate different projects in the energy and environmental industry.

\section{References}

Cahyani S.I., Risk management strategy of power generating of PT Indonesia Power, Proceedings of the ISAHP 2003, Bali, Indonesia, August 7-9, 2003;

Jaber J.O., Jaber Q.M., Sawalha S.A., Mohsen M.S.; Evaluation of conventional and renewable energy sources for space heating in the household sector; Renewable and Sustainable Energy Reviews 12 (2008) 278-289;

Kabir A B M Z and Shihan S M A, Selection of renewable energy sources using analytic hierarchy process, , Proceedings of the ISAHP 2003, Bali, Indonesia, August 7-9, 2003;

Kablan M.M., Decision Support for Energy Conservation Promotion: an Analytic Hierarchy Process approach, Energy Policy 32 (2004) 1151-1158; 
Kagayazo T., Kaneko K., Akai M., Hijikata K., Methodology and evaluation of priorities for energy and environmental research projects, Energy 22 (1997) 121-129;

Lee A.H.I., Chen H.H., Kang H.Y., Multi-criteria decision making on strategic selection of wind farms; Renewable Energy 34 (2009) 120-126;

Limmeechokchai B., Chawana S., Sustainable energy development strategies in the rural Thailand: The case of the improved cooking stove and the small biogas digester, Renewable and Sustainable Energy Reviews 11 (2007) 818-837;

Nagesha N., Balachandra P. Barriers to energy efficiency in small industry clusters: Multi-criteriabased prioritization using the analytic hierarchy process; Energy 31 (2006) 1633-1647;

Saaty TL. The analytic hierarchy process. New York: McGraw-Hill; 1980.

Sri Lanka case study; Energy Conversion and Management 47 (2006) 1179-1191;

Wijayatunga P D.C. , Siriwardena K., Fernando W.J.L.S., Shrestha R. M., Attalage R. A., Strategies to overcome barriers for cleaner generation technologies in small developing power systems:

Xiaohua Wang, Zhenmin Feng, Sustainable development of rural energy and its appraising system in China, Renewable and Sustainable Energy Reviews 6 (2002) 395-404; 